\title{
El trabajo colaborativo y la socioformación: un camino hacia el conocimiento complejo*
}

\author{
José Manuel Vázquez Antonio ${ }^{I}$ \\ (iD http://orcid.org/0000-0002-3182-6847 \\ José Silvano Hernández Mosqueda ${ }^{2}$ \\ (ID http://orcid.org/0000-0002-3179-5577 \\ Jennifer Vázquez-Antonio ${ }^{3}$ \\ (D) $h t t p: / / o r c i d . o r g / 0000-0002-2321-682 X$ \\ Luis Gibran Juárez Hernández ${ }^{4}$ \\ (ID) http://orcid.org/0000-0003-0658-6818 \\ Clara Eugenia Guzmán Calderón 5 \\ (iD http://orcid.org/0000-0003-2855-8447 \\ Centro Universitario CIFE, Sede Cuernavaca, Morelos, México
}

DOI: http://dx.doi.org/10.17081/eduhum.19.33.2648

Recibido: 10 de abril de 2016

Aceptado: 30 de octubre de 2016

\section{Collaborative work and socioformation: a path to complex knowledge}

Palabras clave:

Enfoque socioformativo,

Colaboración, Sinergia,

Pensamiento complejo.

Key words:

Socioformative Approach,

Collaboration, Synergy,

Complex thought.

\section{Resumen}

El propósito de este artículo fue analizar la naturaleza del trabajo colaborativo en el marco del enfoque socioformativo, con el fin de orientar su aplicación y generar nuevas líneas de investigación. Se realizó un estudio documental apoyado en la estrategia de la cartografía conceptual y de sus ocho ejes. Los principales resultados fueron: 1) el trabajo colaborativo en la socioformación se caracteriza por enfatizar en la resolución de problemas del contexto y la metacognición; 2) difiere del aprendizaje en equipo; 3 ) se basa en el desarrollo del pensamiento complejo; y 4) se orienta hacia la sociedad del conocimiento. Se recomiendan nuevos estudios para validar los instrumentos de diagnóstico y la metodología propuesta.

\begin{abstract}
The purpose of this article was to analyze the nature of the collaborative work within the framework of the socio formative approach, in order to guide its application and generate new lines of research. A documentary study was carried out based on the strategy of conceptual cartography with its eight axes. The main results were: 1) the collaborative work in the socio formation is characterized by emphasizing in the resolution of problems of the context and metacognition; 2)differs from team learning; 3 ) is based on the development of complex thought; and 4) is oriented to the knowledge society. New studies are recommended to validate the diagnostic tools and the proposed methodology.
\end{abstract}

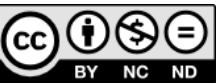

Referencia de este artículo (APA): Vázquez, J., Hernández, J., Vázquez, J., Juárez, L. \& Guzmán, C. (2017). El trabajo colaborativo y la socioformación: un camino hacia el conocimiento complejo. En Revista Educación y Humanismo, 19(33), 334-356. http:// dx.doi.org/10.17081/eduhum.19.33.2648

1. Maestro en Competencias Docentes. Subdirector Académico de la Escuela Normal Rural "Lic. Benito Juárez” de Panotla, Tlaxcala, México. Profesor investigador del Centro Universitario CIFE. profesorjosemanuel@ gmail.com

2. Maestro en Competencias Docentes. Profesor investigador del Centro Universitario CIFE. josesilvanohernandez@ gmail.com

3. Maestra en Educación Superior y Maestría en Desarrollo de Competencias Docentes. Profesora investigadora de la Escuela Normal Rural "Lic. Benito Juárez" de Panotla, Tlaxcala. jenit1976@ gmail.com

4. Doctor en Ciencias Biológicas y de la Salud. Centro Universitario CIFE, luisgibrancife@ gmail.com

5. Investigadora en el Centro Universitario CIFE, en la línea de investigación: Sociedad del conocimiento y tecnologías de la información y la comunicación. klaraguz@gmail.com 


\section{Introducción}

Según Sterh (1994), la sociedad del conocimiento se sustenta en la capacidad de emplear y generar el saber para innovar constantemente el conjunto de las actividades humanas. Tobón, Guzmán, Hernández y Cardona (2015) establecieron que esta nueva sociedad está emergiendo a escala global y demanda la transformación de los procesos de formación, ya que consiste en un conjunto de comunidades que trabajan de manera colaborativa para resolver problemas con una visión global y mediante el apoyo de la tecnología. A diferencia de la sociedad de la información, que se focaliza en producir y aplicar la información en tareas cotidianas (Hopenhayn, 2003), en la sociedad del conocimiento se gestiona, crea, analiza, critica, comparte y aplica el conocimiento en la resolución de problemas en diversos contextos (Hernández, Guerrero \& Tobón, 2015).

Por lo anterior, como ya se ha dicho, es fundamental construir nuevas perspectivas educativas que trasciendan el concepto de aprendizaje y se centren en las nuevas realidades sociales, caracterizadas por el cambio acelerado, la tecnología, las redes sociales y los problemas que afectan a la comunidad (Tobón, González, Nambo \& Vázquez, 2015). Es claro al respecto que los enfoques y modelos educativos vigentes, en su mayoría, se estructuraron para responder a los retos de la sociedad industrial y de la información, como es el caso de la teoría sociocultural (Chaves, 2001; Vygotsky, 1979, 1981), la psicología cognitiva (Bruning,
Schraw \& Ronning, 2002), el constructivismo (Carretero, 2009; Inhelder \& Piaget, 1972), el aprendizaje significativo (Ausubel, 1976; Díaz, 2003; Woolfolk, 2010), la enseñanza para la comprensión (Perkins, 1997; Stone, 1999) y el Aprendizaje Estratégico (Feo, 2015), entre otros. Pero la sociedad del conocimiento requiere articular la teoría con la práctica profesional, con énfasis en la multi y transdisciplina, la incursión en los problemas de la supercomplejidad y el favorecimiento del trabajo en equipo (Janasz \& Sullivan, 2004).

Precisamente, de esta necesidad surge la socioformación, una propuesta latinoamericana para transformar el sistema educativo considerando los retos sociales y ambientales, así como las necesidades de autorrealización personal. El término "socioformación" y su planteamiento teórico-metodológico fue propuesto por Tobón (2001, 2002, 2004). En síntesis, este enfoque aborda el proceso educativo a partir de las dinámicas y retos personales y sociales, considerando el ambiente. Su intención consiste en que las personas aprendan a identificar, interpretar, argumentar y resolver problemas de manera colaborativa, con un sólido proyecto ético de vida y desarrollen su capacidad de emprendimiento (Tobón, Cardona, Vélez \& López, 2015), la gestión del conocimiento en diversas fuentes, la co-creación de saberes y el desempeño metacognitivo (Tobón, 2013a, 2014).

El trabajo colaborativo es un concepto clave en la sociedad del conocimiento (Domínguez- 
Gaona, Crhová \& Molina-Landeros, 2015), pues es preciso que las personas unan sus fortalezas para hacer frente a los desafíos del trabajo laboral, la vida en comunidad y la innovación continua. Además, las actividades de desarrollo e investigación actualmente se estructuran respecto a problemas complejos que rebasan los límites disciplinarios (Gibbons, 1998). Ante este panorama, cabe resaltar las siguientes consideraciones introductorias en torno al trabajo colaborativo:

1. A través de la colaboración se identifican, interpretan, argumentan y resuelven problemas del contexto de manera conjunta (Hernández et al., 2015), lográndose un mayor alcance del que se consigue de manera individual. De modo que esta condición permitiría satisfacer necesidades y contribuir al tejido social, al desarrollo socioeconómico y a la sustentabilidad ambiental (Hernández, Tobón \& Vázquez, 2014).

2. La colaboración es clave para desarrollar el talento de las personas, ya que quienes cuentan con un mayor desarrollo de las competencias se convierten en ejemplo para los demás y en una fuente de estimulación y creatividad. Por lo tanto, con ella se promueve la transferencia de conocimientos y habilidades (Loan-Clarke $\&$ Preston, 2002). De esta manera, la colaboración es un factor relevante en la promoción y transmisión de capital humano, científico y técnico (Lee \& Bozeman, 2005).

3. La colaboración es esencial para que las personas se apoyen de manera mutua (Hernández, Tobón, González \& Guzmán,
2015) y se brinden compañía intelectual (Loan-Clarke \& Preston, 2002).

4. La colaboración es un proceso en el que los miembros del grupo deben aprender a respetar el conocimiento y habilidades que cada uno aporta (Cano, 1996). Esto último favorece la cohesión social (Lanza \& Barrios, 2012) y, por tanto, el respeto a las ideas de los demás por medio de la escucha activa y la tolerancia, lo que es importante para la convivencia y la cultura de la paz (Hernández, Nambo, López, \& Núñez, 2015).

5. Mediante la colaboración se promueve la inclusión, ya que se aceptan a todos como son, independientemente de su condición física, cognitiva o sociocultural. Además, estimula el apoyo de los integrantes para lo que los requieran (Tobón et al., 2015).

Por lo anteriormente expresado, es fundamental poseer una argumentación conceptual precisa del trabajo colaborativo que apoye la construcción de la sociedad del conocimiento (Ortega-Carbajal, Hernández \& Tobón, 2015a). Ya se ha expresado que los planteamientos actuales hacen referencia a otros contextos sociales como la sociedad industrial (Germani, 1962; Ulrich, 2003) y la sociedad de la información (Lucas, 2000; Martín, 1997, 2007), pero no se enfocan en los retos de la sociedad del conocimiento. Por otra parte, aunque se ha avanzado en la conceptualización del trabajo colaborativo (Tobón \& Vázquez, 2015), aún existen aspectos que requieren mayor claridad, como la caracterización, metodología y diferen- 
ciación respecto a conceptos cercanos, tales como la cooperación, el trabajo en equipo y el trabajo en grupo.

Por lo tanto, el propósito del presente artículo consistió en presentar un estudio conceptual del trabajo colaborativo que contribuya a otorgar una mayor claridad y solidez teórica y metodológica, en el marco del enfoque socioformativo, el pensamiento complejo, la sociedad del conocimiento y la tierra-patria (Morin \& Kern, 1993); con lo que se pretende promover y emprender futuras investigaciones empíricas en el área. También se busca apoyar la implementación de la colaboración en los procesos de gestión del talento humano, así como en la educación y los proyectos socioeconómicos (Hernández, 2013a).

\section{Metodología}

\section{Tipo de Estudio}

Se realizó un análisis documental (Pinto \& Gálvez, 1996) en la línea cualitativa sobre el trabajo colaborativo, su vinculación con el pensamiento complejo y su contribución con la sociedad del conocimiento. El análisis documental consistió en buscar, seleccionar, organizar y analizar un conjunto de materiales escritos para responder una o varias preguntas sobre un tema y, de esta forma, ampliar el conocimiento sobre lo estudiado con el fin de realizar nuevos aportes. Por lo anterior, se puede afirmar que el estudio documental busca recuperar $\mathrm{y}$ trascender el conocimiento acumulado sobre un objeto de estudio específico (Londoño, Maldonado \& Calderón, 2014).

\section{Estrategia de investigación}

El estudio documental se apoyó en la cartografía conceptual. Esta estrategia metodológica propone ocho categorías para construir, analizar y sistematizar el conocimiento en torno a un concepto o teoría. Fue adaptada por Tobón (2004, 2015a) en el marco del enfoque socioformativo y se basa en los mentefactos conceptuales, como los mapas conceptuales (Novak, 2010) y mapas mentales (Buzán, 2004). Existen estudios empíricos que demuestran el impacto y pertinencia de dicha estrategia de investigación en la formación de personas y en la gestión del conocimiento (Ortega-Carbajal, Hernández \& Tobón, 2015b). En la Tabla 1 se describen los ejes clave.

Tabla 1. Ejes clave de la cartografía conceptual que se abordan en torno al concepto "trabajo colaborativo" desde la socioformación

\begin{tabular}{|c|c|}
\hline Eje de Análisis & Pregunta Central \\
\hline 1. Noción & $\begin{array}{l}\text { ¿Cuál es la etimología, el desarrollo histó- } \\
\text { rico y la definición actual de trabajo cola- } \\
\text { borativo en la socioformación? }\end{array}$ \\
\hline 2. Categorización & $\begin{array}{l}\text { ¿Aquécategoría(oclase) mayorpertenece } \\
\text { el trabajo colaborativo? }\end{array}$ \\
\hline 3. Caracterización & $\begin{array}{l}\text { ¿Cuáles son las características centrales del } \\
\text { trabajo colaborativo desde la socioforma- } \\
\text { ción? }\end{array}$ \\
\hline 4. Diferenciación & $\begin{array}{l}\text { ¿De cuáles otros conceptos cercanos y que } \\
\text { estén en la misma categoría se diferencía } \\
\text { el trabajo colaborativo desde la sociofor- } \\
\text { mación? }\end{array}$ \\
\hline 5. Clasificación & $\begin{array}{l}\text { ¿En qué subclases o tipos se clasifica el } \\
\text { trabajo colaborativo en la socioformación? }\end{array}$ \\
\hline 6. Vinculación & $\begin{array}{l}\text { ¿Cómo se vincula el trabajo colaborativo } \\
\text { con determinadas teorías, procesos socio- } \\
\text { culturales y referentes epistemológicos que } \\
\text { estén por fuera de la categorización? }\end{array}$ \\
\hline 7. Metodología & $\begin{array}{l}\text { ¿Cuáles son los elementos metodológicos } \\
\text { mínimosque implica el abordaje del traba- } \\
\text { jo colaborativo en la socioformación? }\end{array}$ \\
\hline 8. Ejemplificación & $\begin{array}{l}\text { ¿Cuál podría ser un ejemplo relevante y } \\
\text { pertinente de aplicación del trabajo cola- } \\
\text { borativo desde el enfoque socioformativo? }\end{array}$ \\
\hline
\end{tabular}




\section{Criterios para la búsqueda y selección de los}

\section{documentos}

El estudio documental se basó en los siguientes criterios: 1) se buscaron artículos, libros y capítulos de libros en bases de datos como Google Académico, Science Direct, Scielo, Redalyc y Latindex; 2) los artículos debían estar publicados en revistas indexadas; 3) los libros, capítulos de libros y manuales debían poseer autor, título, fecha y editorial; y 4) se emplearon las siguientes palabras clave: socioformación, trabajo colaborativo y pensamiento complejo. Todos los documentos debían contribuir a clarificar el concepto de trabajo colaborativo desde la socioformación. No se consideraron otros enfoques ni propuestas, en función del propósito del estudio.

\section{Documentos analizados}

En la Tabla 2 se presenta una síntesis de los documentos encontrados y seleccionados para el presente estudio, que cumplieron con los criterios establecidos.

Tabla 2. Documentos analizados

\begin{tabular}{|l|l|l|l|}
\hline \multicolumn{1}{|c|}{$\begin{array}{c}\text { Tipo de } \\
\text { documento }\end{array}$} & Cantidad & $\begin{array}{c}\text { De origen } \\
\text { latinoamericano }\end{array}$ & $\begin{array}{l}\text { De otras } \\
\text { regiones }\end{array}$ \\
\hline $\begin{array}{l}\text { Artículos de } \\
\text { revistas } \\
\text { indexadas }\end{array}$ & 42 & 33 & 9 \\
\hline Libros & 45 & 35 & 10 \\
\hline $\begin{array}{l}\text { Capítulos de } \\
\text { libros }\end{array}$ & 3 & 3 & 0 \\
\hline $\begin{array}{l}\text { Otros } \\
\text { documentos }\end{array}$ & 3 & 2 & 1 \\
\hline Fuente: Elaboración propia & &
\end{tabular}

\section{Resultados}

A continuación, se describe la sistematización del conocimiento en torno al trabajo colaborativo siguiendo los ocho ejes de la cartografía conceptual.

\section{Noción de trabajo colaborativo}

El término colaboración está conformado por los siguientes componentes léxicos latinos: el prefijo $c o$, que es equivalente a junto; el verbo laborare, que puede traducirse como trabajar y el sufijo -ción, que es sinónimo de acción y efecto (RAE, 2017). Por lo anterior, una primera aproximación al concepto de colaboración es: acción y efecto de colaborar. En general, puede decirse por lo anterior que el trabajo colaborativo consiste en trabajar con otra u otras personas para alcanzar una meta.

En el campo de la formación, existen múltiples perspectivas en torno al trabajo colaborativo. Por ejemplo, desde el aprendizaje cooperativo, Ferreiro (2006) plantea:

... Este método pedagógico es ante todo, una filosofía de vida y una concepción de enseñanza que orienta y anima a aprender junto a los demás; es así mismo un modelo educativo que establece una dinámica de trabajo muy provechosa, dadas las relaciones de cooperación entre todos los componentes de la institución; y es, también, una forma de organizar el proceso de enseñanza en el salón de clases, que incide en la formación integral de los educandos, en el modo profesional de 
trabajo del maestro y en el comportamiento de

ellos y de los alumnos y demás miembros de

la escuela en su proyección a la comunidad...

(p.26)
El desarrollo histórico del trabajo colaborativo ha estado ligado a los diferentes paradigmas psicopedagógicos. Estos enfoques han enriquecido la comprensión de este proceso perfeccionando el ámbito de la gestión del talento

Tabla 3. Contribuciones de los diferentes enfoques y modelos psicopedagógicos al trabajo colaborativo

\begin{tabular}{|c|c|c|c|}
\hline Enfoque & $\begin{array}{c}\text { Concepto de trabajo } \\
\text { colaborativo }\end{array}$ & Énfasis & Acciones en la metodología \\
\hline $\begin{array}{l}\text { Modelo conductual } \\
\text { (Beltrán \& Bueno Eds., } \\
\text { 1997). }\end{array}$ & $\begin{array}{l}\text { Adquisición de conoci- } \\
\text { mientos y destrezas en } \\
\text { la interacción. }\end{array}$ & Desarrollo cognitivo & $\begin{array}{l}\text { Lainteracción entre iguales es altamente impor- } \\
\text { tanteparala consecución de sus propios objetivos } \\
\text { académicos. }\end{array}$ \\
\hline $\begin{array}{l}\text { Modelo cognoscitivista } \\
\text { (Beltrán \& Bueno, Eds. } \\
\text { 1997). }\end{array}$ & $\begin{array}{l}\text { Interdependencia de } \\
\text { meta e igualdad de } \\
\text { estatus entre los miem- } \\
\text { bros del grupo. }\end{array}$ & $\begin{array}{l}\text { Prepara al individuo para } \\
\text { vivir en sociedad, en } \\
\text { adquisición de destrezas } \\
\text { cognitivas, afectivas, } \\
\text { motrices y sociales. }\end{array}$ & $\begin{array}{l}\text { Semantiene cuandolos principales objetivos } \\
\text { propuestos son comunes atodos los miembros del } \\
\text { grupo. } \\
\text { Difunden en el grupo el sentido de responsabilidad } \\
\text { común y de ayuda mutua. }\end{array}$ \\
\hline $\begin{array}{l}\text { Modelo constructivista } \\
\text { (Díaz-Barriga \& } \\
\text { Hernández, 2010) }\end{array}$ & $\begin{array}{l}\text { Consiste en trabajar } \\
\text { juntos para alcanzar } \\
\text { objetivos comunes. }\end{array}$ & $\begin{array}{l}\text { Los alumnos trabajan } \\
\text { juntos para maximizarsu } \\
\text { propioaprendizajeyelde } \\
\text { los demás }\end{array}$ & $\begin{array}{l}\text { Especificar objetivos de enseñanza. } \\
\text { Planear materiales de enseñanza. } \\
\text { Asignarestudiantes yrolesparaasegurar lainter- } \\
\text { dependencia positiva. } \\
\text { Explicar la tarea académica. } \\
\text { Estructurar la meta grupal,la valoración individual } \\
\text { y la cooperación. } \\
\text { Especificar los comportamientos deseables y } \\
\text { monitorear la conducta. } \\
\text { Proporcionar asistencia, interviniendo para enseñar } \\
\text { habilidades de colaboración. } \\
\text { Evaluarlacalidad y cantidad del aprendizaje de } \\
\text { los alumnos. } \\
\text { Valorar el buen funcionamiento del grupo. }\end{array}$ \\
\hline $\begin{array}{l}\text { Modelo } \\
\text { Socioconstructivista } \\
\text { (DOF, 2012) }\end{array}$ & $\begin{array}{l}\text { Los estudiantes traba- } \\
\text { jan juntos en grupos re- } \\
\text { ducidos para maximizar } \\
\text { su aprendizaje como el } \\
\text { de sus compañeros }\end{array}$ & Interdependencia positiva & $\begin{array}{l}\text { Se enseña a aprender en el marco de experiencias } \\
\text { colectivas a través de comunidades deaprendizaje } \\
\text { como espacios que promueven la práctica reflexiva } \\
\text { mediante la negociación de significados y la solu- } \\
\text { ción de problemas complejos. }\end{array}$ \\
\hline $\begin{array}{l}\text { Enfoque socioformativo } \\
\text { (Tobón, González, Nambo } \\
\text { \& Vázquez, 2015) }\end{array}$ & $\begin{array}{l}\text { Las personas trabajan } \\
\text { unas con otras mediante } \\
\text { actividades articuladas } \\
\text { para lograr una meta } \\
\text { común. Para ello es } \\
\text { necesario comunicarse } \\
\text { con asertividad, unir } \\
\text { las fortalezas y resolver } \\
\text { los conflictos que se } \\
\text { presentan. }\end{array}$ & $\begin{array}{l}\text { Resolución de problemas } \\
\text { del contexto }\end{array}$ & $\begin{array}{l}\text { Se organiza el trabajo colaborativo entre los } \\
\text { estudiantes opersonasque participan enelproceso } \\
\text { formativo, buscando que se articulen las acciones } \\
\text { de todos para interpretar, argumentar y contribuir a } \\
\text { resolver el problema. } \\
\text { Puede darse con diversas modalidades, por ejem- } \\
\text { plo: 1) todos trabajan en un mismo proyecto; } 2 \text { ) los } \\
\text { estudiantes se organizan por equipos ycada equipo } \\
\text { aborda un problema específico del problema ge- } \\
\text { neral; y 3) cada estudiante trabaja en un proyecto, } \\
\text { pero durante el proceso, se comparten los avances } \\
\text { con los pares y se tiene el apoyo de estos, así como } \\
\text { del docente mediador. }\end{array}$ \\
\hline
\end{tabular}

Fuente: Elaboración propia 
humano y la educación con estrategias (Ortega et al., 2015a). Lo anterior se ha concretado mediante el conductismo, el humanismo, el constructivismo y el socioconstructivismo. En la Tabla 3, se describen las contribuciones de estos diferentes enfoques, así como la definición de trabajo colaborativo que proponen y sus énfasis en la metodología.

Como puede verse, la socioformación retoma las contribuciones anteriores y propone un cambio de enfoque del trabajo colaborativo. En lugar de centrarse en el acto de colaborar en sí mismo se focaliza en resolver problemas del contexto a través de acciones coordinadas de varias personas. De manera más específica, el trabajo colaborativo desde la socioformación se entiende como un proceso mediante el cual varias personas comparten ideas, recursos $\mathrm{y}$ saberes para identificar, interpretar, argumentar y resolver un determinado problema, buscando el logro de una meta acordada, mediante la unión de sus fortalezas y trabajando con comunicación asertiva (Tobón, 2013a; 2014).

Un elemento clave e inherente al trabajo colaborativo es el inter-aprendizaje, que consiste en lograr la formación integral y perfeccionar las competencias necesarias para afrontar los retos y problemas del contexto mediante la interacción con otros en proyectos. Implica dialogar, considerar los intereses individuales, acordar metas comunes, hacer planes de acción en conjunto, abordar la coevaluación y contribuir en la formación de otros pares (Tobón, 2013a).

\section{Categorización del trabajo colaborativo}

El trabajo colaborativo es una estrategia que la socioformación ha retomado para contribuir con la construcción y consolidación de la sociedad del conocimiento (Marcelo, 2001; Mateo, 2006; Mora, 2004; Tedesco, 2000; Tobón, González, Nambo \& Vázquez, 2015). Este enfoque pretende que las personas se formen elaborando y ejecutando proyectos relevantes para resolver problemas del contexto. Se caracteriza por favorecer la gestión y co-creación del conocimiento, el trabajo colaborativo y la gestión del cambio y afrontamiento de la incertidumbre (Tobón et al., 2015). En este sentido, la socioformación difiere de otros enfoques utilizados en la sociedad del conocimiento como el conectivismo (Siemens, 2005), en donde el aprendizaje es conocimiento aplicable, puede estar fuera de la persona y busca conectar conjuntos de información especializada.

La socioformación, a su vez, responde a los retos de la sociedad del conocimiento. El término sociedad del conocimiento apareció por primera vez en 1969 (Krüger, 2006), y es el producto de los cambios sociales que se han presentado en las últimas tres décadas, en las cuales se pasó de la sociedad industrial a la sociedad de la información por la emergencia de las tecnologías de la información y la globalización. La sociedad de la información está asociada a los procesos tecnológicos y a la difusión de la información, y se centra en la producción, manejo y distribución de la información para resolver tareas cotidianas. Trejo (2001) resalta en ella las 
siguientes características: exuberancia, omnipresencia, irradiación, velocidad, multilateralidad/centralidad, interactividad/unilateralidad, desigualdad, heterogeneidad, desorientación y ciudadanía pasiva.

En cambio, la sociedad del conocimiento es la que ha comenzado a emerger en todo el mundo e implica interacción a escala global (Mora, 2004). Existen diversas definiciones de sociedad del conocimiento, y desde la socioformación se entiende como un conjunto de comunidades que gestionan, co-crean, socializan y aplican los saberes en la identificación, interpretación, argumentación y resolución de los problemas del contexto con sentido crítico, trabajo colaborativo, ética, gestión del cambio y uso de las TIC (Tobón et al., 2015). Además, promueve comunidades que buscan la calidad de vida, el tejido social, el desarrollo socioeconómico y la sustentabilidad ambiental, superando las necesidades estructurales y generando mejores ambientes de convivencia, dado que se basan en la aplicación de valores universales como la responsabilidad, la equidad, la honestidad y el respeto. En la Tabla 4 se muestran las principales características de la sociedad del conocimiento desde la socioformación:

\section{Caracterización del trabajo colaborativo}

El trabajo colaborativo presenta las siguientes características desde la socioformación:

- Acuerdo de una meta en el marco de un problema del contexto: Un elemento clave en todo proceso de trabajo colaborativo es que los integrantes acuerden una meta común. Johnson y Johnson (citado en Díaz-Barriga \& Hernández, 2010) opinan que de preferencia esto debe involucrar la solución de problemas. Esta meta común permite generar uno o varios productos que demuestran el desempeño de los integrantes del equipo y

Tabla 4. Principales características de la sociedad del conocimiento desde la socioformación

\begin{tabular}{|c|c|c|}
\hline $\begin{array}{c}\text { Gestión y co-creación del conocimiento } \\
\text { (Ortega et al., 2015a) }\end{array}$ & $\begin{array}{c}\text { Gestión de cambio y afrontamiento } \\
\text { de la incertidumbre } \\
\text { (Tobón \& Núñez, 2006) }\end{array}$ & $\begin{array}{c}\text { Uso de las TIC } \\
\text { (Tobón et al., 2015) }\end{array}$ \\
\hline $\begin{array}{l}\text { Como su nombre lo indica gestiona y crea } \\
\text { conocimientos para alcanzar objetivos } \\
\text { establecidos, se compone de los siguientes } \\
\text { elementos mediante la colaboración: } \\
\text { - Identificar los problemas } \\
\text { - Buscar fuentes pertinentes } \\
\text { - Procesar el conocimiento } \\
\text { - Organizar el conocimiento } \\
\text { - Contextualizar el conocimiento } \\
\text { - Realizar adaptacionesenel conocimiento } \\
\text { - Crear e innovar el conocimiento } \\
\text {-Aplicarelconocimiento alaresolución de } \\
\text { problemas. }\end{array}$ & $\begin{array}{l}\text { Considerando que el contexto es } \\
\text { cambiante, será necesario gestionar } \\
\text { el conocimiento para enfrentar las } \\
\text { situaciones según su complejidad y } \\
\text { multidimensionalidad. } \\
\text { La incertidumbre, por su parte, consiste } \\
\text { en la dificultad para establecer con } \\
\text { determinacióny claridadelimpactodelas } \\
\text { acciones que se emprenden frente a una } \\
\text { situación relevante. }\end{array}$ & $\begin{array}{l}\text { Apoyan actividades para realizar } \\
\text { participaciones en diferentes momentos } \\
\text { de manera sincrónica y asincrónica, su } \\
\text { aplicación contribuye en la solución de } \\
\text { problemascomolapobreza,elhambre, la } \\
\text { violencia, etc. } \\
\text { Permite generar nuevos escenarios } \\
\text { formativosapartirdelaflexibilidady } \\
\text { asistencia remota. }\end{array}$ \\
\hline
\end{tabular}

Fuente: Elaboración propia 
ayuda a los miembros a articular sus acciones y a resolver las dificultades que se presenten en el camino (Hernández, 2015a).

- Actuación con un plan de acción: El plan de acción debe ser acordado por todos los miembros del equipo de trabajo colaborativo. Como parte de sus elementos clave se debe considerar: actividades a realizar, tiempos, responsables y recursos necesarios. Un aspecto importante en este sentido es revisar el plan de acción a medida que se avanza en el trabajo, a fin de implementar mejoras o cambios según las circunstancias que se presenten, así como las evaluaciones del proceso y logros obtenidos (Hernández, Tobón \& Guerrero, 2016; Parra-Acosta, Tobón \& Loya, 2015).

- Desempeño sinérgico: Es esencial que los integrantes del equipo compartan y complementen sus habilidades, actitudes y conocimientos para el logro de la meta acordada con creatividad e impacto. Para lograrlo, deben aprender a conocerse y hacer acuerdos considerando sus principales fortalezas. El resultado debe ser superior a lo que podría lograr cada integrante de manera individual, así que debe haber distribución de roles: coordinación, sistematización, gestión de la calidad y dinamización. Estos deben ser flexibles, móviles y alternarse entre los estudiantes conforme a los retos que se tengan, para que de esa forma el liderazgo no se limite a uno o dos estudiantes, sino que se comparta entre todos (Hernández \& Vizcarra, 2015).
A continuación, se muestran algunas acciones clave de cada rol:

- Actuación con metacognición: La metacognición es un proceso fundamental, que debe darse de forma permanente en la colaboración (Tobón, 2013f). De acuerdo con Antonijevick y Chadwick (1981), la capacidad metacognoscitiva es un atributo del pensamiento humano que se vincula con la habilidad que tiene una persona para conocer lo que conoce, planificar estrategias para procesar información, tener conciencia de sus propios pensamientos durante el acto de solución de problemas, así como para reflexionar acerca del problema y evaluar la productividad de su propio funcionamiento intelectual. Para autores como Swanson (1990) y Yussen (1985), la metacognición alude a una serie de operaciones cognoscitivas ejercidas por un interiorizado conjunto de mecanismos que permiten recopilar, producir y evaluar información, así como controlar y autorregular el funcionamiento intelectual propio. Por su parte, Feo (2015) considera que las estrategias metacognitivas implican un ejercicio autoconsciente para identificar las debilidades $\mathrm{y}$ fortalecer bondades frente a una situación problemática. Desde el enfoque socioformativo, actuar con metacognición consiste en lograr el mejoramiento continuo con base en una meta común, la reflexión y la actuación tanto personal como colectiva de quienes participan en el proceso para valorar sus logros, identificar los aspectos a mejorar y aplicar las acciones de mejora oinnovación 
Tabla 5. Roles en el trabajo colaborativo propuestos por la socioformación

\begin{tabular}{|c|c|c|}
\hline Rol & Síntesis & Acciones claves \\
\hline Coordinador & $\begin{array}{l}\text { Lidera la actividad } \\
\text { Promueve los valores en el trabajo } \\
\text { Impulsa el liderazgo compartido }\end{array}$ & $\begin{array}{l}\text { Busca acordar la meta a lograr y el plan de acción a ejecutar, considerando } \\
\text { un determinado problema. } \\
\text { Crea un ambiente de confianza en el cual se respetan las ideas de todos. } \\
\text { Motiva a los integrantes a contribuir con la meta. }\end{array}$ \\
\hline Sistematizador & $\begin{array}{l}\text { Se encarga de documentar, guardar } \\
\text { y recuperar la información en torno } \\
\text { a las actividades y productos. }\end{array}$ & $\begin{array}{l}\text { Lleva las actas del trabajo colaborativo. } \\
\text { Sistematiza la información obtenida por los integrantes. } \\
\text { Estápendiente de laelaboracióndelosinformes del trabajocolaborativo. } \\
\text { Presenta informes de los acuerdos. }\end{array}$ \\
\hline Gestordecalidad & $\begin{array}{l}\text { Se encarga de buscar que se logre } \\
\text { la meta acorde con los criterios } \\
\text { establecidos, propiciando un alto } \\
\text { grado de creatividad y pertinencia. }\end{array}$ & $\begin{array}{l}\text { Verificaelcumplimiento de las actividades de acuerdo con el plan de acción } \\
\text { y hace sugerencias para hacerlas lo mejor posible. } \\
\text { Verifica la calidad de los productos obtenidos y hace sugerencias para } \\
\text { mejorarlos. } \\
\text { Presenta informes periódicos del plan de acción y del grado de logro de las } \\
\text { metas propuestas en los criterios. } \\
\text { Apoya en la gestión del tiempo, considerando las actividades que se deben } \\
\text { realizar. }\end{array}$ \\
\hline Dinamizador & $\begin{array}{l}\text { Se encarga de generar un buen } \\
\text { ambiente en el trabajo colaborativo } \\
\text { y de implementar acciones para } \\
\text { superar las posibles resistencias y } \\
\text { dificultades que se presenten. }\end{array}$ & $\begin{array}{l}\text { Evalúa la dinámica del trabajo colaborativo y hace sugerencias para su } \\
\text { mejora. } \\
\text { Busca que se identifiquen con claridad las fortalezas de cada integrante para } \\
\text { el logro de la meta en común. } \\
\text { Implementa acciones para lograrel trabajo colaborativo y que todos cumplan } \\
\text { sus compromisos. } \\
\text { Está pendiente de la entrega de tareas y del cumplimiento de compromisos } \\
\text { por parte de los integrantes. }\end{array}$ \\
\hline
\end{tabular}

Fuente: Tobón (2013a)

que contribuyan a resolver el problema del contexto y el logro de la meta común (Hernández, 2013b).

- Interacción con comunicación asertiva: Consiste en que las personas, al desarrollar el trabajo colaborativo, se expresen y brinden sus contribuciones con amabilidad, respetando los derechos de los demás. Implica escuchar, dialogar y resolver conflictos por medio del establecimiento de acuerdos sobre elementos fundamentales (Terroni, 2009; Acosta, Tobón \& Loya, 2015). Para ello, son necesarios los valores universales, que han de ser empleados en todos los procesos de formación y colaboración. Otro aspecto a tomar en cuenta para lograr una comunicación con asertividad es que las opiniones y contribuciones de todos los integrantes sean objetivas y estén debidamente fundamentadas, apoyándose en referentes validados científicamente, de manera que contribuyan a tomar decisiones consensuadas entre los miembros y favorezcan el desempeño sinérgico y el logro de la meta (Tobón, 2013f).

- Responsabilidad personal: El éxito en el trabajo colaborativo exige que todos asuman las responsabilidades contraídas en cuanto a sus contribuciones y actividades, considerando el rol que les haya sido asignado y las acciones inherentes, así como el plan de 
acción que se haya establecido en el grupo.

Si esta condición no se cumple, no habrá una verdadera colaboración. La responsabilidad personal implica que cada participante aporte y que nadie deje de contribuir en el logro de las metas propuestas por el grupo. El éxito particular es el éxito del grupo (Pastor, 2007; Tobón \& Vázquez, 2015).

\section{Diferenciación entre el trabajo colabo- rativo y otras formas $y$ modalidades de trabajo}

Desde la socioformación, el trabajo colaborativo se diferencia en tres formas y modalidades de trabajo: a) trabajo en masa (Bartolucci, 2002), b) trabajo en grupo (Onrubia, Colomina
\& Engel, 2008) y c) trabajo cooperativo (Brufee, 1995; Zañartu, 2003, citadas en Maldonado, 2007). A continuación, se describen las principales diferencias:

La revisión de otras modalidades de trabajo grupal, desde otros enfoques psicopedagógicos, permite diferenciar y precisar que, en el trabajo colaborativo desde la socioformación, se pone énfasis en que las personas persigan metas como el desarrollo individual y la madurez de los participantes, su integración y responsabilidades sociales, la autorrealización a través de la interacción en un espacio relativamente libre de control, así como el enfrentamiento de su propia existencia (Calzadilla, 2002).

Tabla 6. Diferencias del trabajo colaborativo desde la socioformación respecto a otras modalidades de trabajo

\begin{tabular}{|c|c|c|}
\hline & Características & $\begin{array}{c}\text { Diferencias y ventajas del trabajo colaborativo desde } \\
\text { la socioformación }\end{array}$ \\
\hline $\begin{array}{l}\text { Trabajo en masa } \\
\text { (Bartolucci, } \\
\text { 2002) }\end{array}$ & $\begin{array}{l}\text { Los estudiantes hacen lo que les dice el profesor o lo que } \\
\text { disponen sus otros compañeros. } \\
\text { No hay análisis crítico de las actividades ni contribuciones } \\
\text { creativas. } \\
\text { Las metas a lograr son impuestas y en la mayoría de } \\
\text { ocasiones dichas metas no se establecen en el marco de } \\
\text { un problema del contexto. } \\
\text { Los integrantes del grupo no aportan más allá de lo que } \\
\text { se les haya dispuesto hacer o no se les permite aportar. }\end{array}$ & $\begin{array}{l}\text { En el trabajo colaborativo el papel del docente consiste } \\
\text { en mediar la formación de los estudiantes a partir de la } \\
\text { resolución de problemas del contexto. En consecuencia, } \\
\text { las metas de aprendizaje se formulan a partir de los } \\
\text { problemas y en congruencia con el currículo. De } \\
\text { esta forma se promueve la autonomía y el liderazgo } \\
\text { compartido al interior de los equipos de trabajo. }\end{array}$ \\
\hline $\begin{array}{l}\text { Trabajo en grupo } \\
\text { (Onrubia, } \\
\text { Colomina \& } \\
\text { Engel, 2008) }\end{array}$ & $\begin{array}{l}\text { Los alumnos acuerdan ayudarse unos a otros en } \\
\text { actividades dirigidas a lograr las metas de cada persona. } \\
\text { Esto genera la distribución de los productos o evidencias } \\
\text { a generar, lo cual deja de lado las metas comunes. }\end{array}$ & $\begin{array}{l}\text { En el trabajo colaborativo, cada miembro del grupo } \\
\text { contribuye a la resolución conjunta del problema; la } \\
\text { colaboración depende, por ello, del establecimiento del } \\
\text { lenguajey significados comunes respecto a la tarea,y de } \\
\text { una meta común al conjunto de participantes. }\end{array}$ \\
\hline $\begin{array}{l}\text { Trabajo } \\
\text { cooperativo } \\
\text { (Maldonado, } \\
\text { 2007) }\end{array}$ & $\begin{array}{l}\text { El profesor asume la responsabilidad del aprendizaje de } \\
\text { sus alumnos y por ello estructura el trabajo y designa las } \\
\text { tareas a realizar en cada grupo o equipo de estudiantes. } \\
\text { La tarea o consigna principal se divide en subtareas } \\
\text { y cada alumno la cumple de forma independiente. El } \\
\text { conocimiento logrado por los estudiantes es mayormente } \\
\text { memorístico, básico y difícilmente se dan espacios para } \\
\text { el razonamiento, la discusión y los cuestionamientos } \\
\text { sobre lo aprendido. }\end{array}$ & $\begin{array}{l}\text { El trabajo colaborativo desde la socioformación, se } \\
\text { constituye por grupos heterogéneos. El liderazgo y } \\
\text { responsabilidad son compartidos por los integrantes, por } \\
\text { lo tanto, el roldel docente mediador es de seguimiento y } \\
\text { retroalimentación. El objetivo primordial no es completar } \\
\text { una tarea sino que se logre un aprendizaje relevante a } \\
\text { partir de la solución conjunta de un problema y de la } \\
\text { buena relación entre los miembros del grupo. }\end{array}$ \\
\hline
\end{tabular}

Fuente: Elaboración propia 


\section{Clasificación del trabajo colaborativo}

Desde la socioformación, el trabajo colaborativo se divide en dos clases de acuerdo con la modalidad donde se aplica:

Tabla 7. Modalidades de trabajo colaborativo desde la socioformación

\begin{tabular}{|l|l|}
\hline Modalidad & Características \\
\hline $\begin{array}{l}\text { Trabajo } \\
\text { colaborativo } \\
\text { presencial }\end{array}$ & $\begin{array}{l}\text { Se realiza con la reunión física o virtual } \\
\text { sincrónica de las personas. No es necesario que } \\
\text { todo lo hagan en reunión, sino que cuando se } \\
\text { trata de establecer acuerdos o hacer actividades } \\
\text { que requieren del trabajo de varios o todos los } \\
\text { integrantes, esto se hace en un determinado } \\
\text { lugar físico, con o sin apoyo de un recurso de } \\
\text { comunicación. }\end{array}$ \\
\hline $\begin{array}{l}\text { Trabajo } \\
\text { colaborativo } \\
\text { virtual }\end{array}$ & $\begin{array}{l}\text { Se realiza a partir de las tecnologías de la } \\
\text { información y la comunicación y de forma } \\
\text { principalmente asincrónica (también puede ser } \\
\text { sincrónica, pero con menor frecuencia), tanto } \\
\text { para conocerse y tomar acuerdos como para } \\
\text { planear y ejecutar determinadas actividades } \\
\text { que requieren la cooperación de dos o más } \\
\text { integrantes. Esto incluye la comunicación por } \\
\text { celular y equipos de cómputo con acceso a } \\
\text { internet (redes sociales, plataformas virtuales, } \\
\text { correo electrónico, Google docs, Drive, etc.). }\end{array}$ \\
\hline
\end{tabular}

Fuente: Elaboración propia

En suma, cabe precisar que cada una de las modalidades de trabajo colaborativo expuestas tiene implicaciones específicas en las relaciones interpersonales, lo anterior se puede determinar de la siguiente forma de acuerdo con cada modalidad de trabajo colaborativo: a) interacción/comunicación física de las personas entre sí mismas "comunicación cara-cara" (Nobles, Londoño, Martínez, Ramos, Santa \& Cotes, 2016) y, b) interacción/comunicación virtual de las personas. Respecto a esta última forma de interacción/comunicación, es importante tener en cuenta estudios empíricos que sirvan de referencia para establecer y forma- lizar las dinámicas (sincrónicas y asincrónicas) de trabajo colaborativo virtual, con la intención de evitar problemas y/o patologías asociadas al uso excesivo de esta tecnología; pues tal como lo establecen Nobles, et al. (2016) si bien es cierto las relaciones sociales mediante el uso de la tecnología son positivas, existe de forma paralela una influencia negativa que disminuye los encuentros personales entre el estudiante $\mathrm{y}$ otros miembros de su círculo social (comunicación cara-cara).

\section{Vinculación del trabajo colaborativo con determinadas teorías y procesos sociales}

El trabajo colaborativo desde la socioformación se relaciona con el pensamiento complejo y la inclusión, a partir de los siguientes planteamientos:

El pensamiento complejo se refiere a la capacidad de interconectar distintas dimensiones de lo real (Morin, 1994), pues posee una intención globalizadora pero que, a la vez, reconoce la especificidad de las partes. El pensamiento complejo constituye un método de construcción del saber humano desde un punto de vista hermenéutico, o sea, interpretativo y comprensivo, retomando la explicación, cuantificación y objetivación (Tobón, 2012b). Por ende, el pensamiento complejo constituye una nueva racionalidad en el abordaje del mundo y del ser humano, donde se entretejen las partes y elementos para comprender los procesos de su interrelación, recursividad, organización, diferencia, oposición y complementación, dentro de factores de orden y de incertidumbre (Tobón, 2013b). 
Una diferencia importante entre el pensamiento complejo y la epistemología tradicional consiste en que la última solo asume el conocimiento desde el ámbito cognitivo, en tanto el primero lo aborda como un proceso que es a la vez biológico, cerebral, espiritual, lógico, lingüístico, cultural social e histórico, por lo cual se enlaza con la vida humana y la relación social (Morin, 1994).

Algunos ejes centrales del pensamiento complejo son:

- Las nociones antagónicas se unen sin perder su diferenciación y particularidad (principio dialógico), que se excluyen y rechazan en el paradigma clásico (Morin, 1993).

- Los procesos se autoproducen y autoorganizan, en tanto los efectos producen causas y las causas producen efectos (recursión organizacional) (Morin, 1996, 1997).

- Hay sistemas en los cuales la parte está en el todo y, a la vez, el todo está en cada una de las partes (principio hologramático) (Morin, 1996, 1997); esto implica la necesidad de conocer el todo para comprender las partes, y estudiar las partes para conocer el todo.

- El pensamiento complejo no se opone al pensamiento simple; por el contrario, propone abordar la construcción del conocimiento desde el pensamiento que separa y que reduce junto con el pensamiento que distingue $\mathrm{y}$ que religa (Tobón, 2013b). Explica Morin (2000): "no se trata de abandonar el conocimiento de las partes por el conocimiento de las totalidades ni el análisis por la síntesis; es necesario conjugarlos" (p.36).
A partir de lo anterior, la socioformación considera que el pensamiento complejo hace las siguientes contribuciones al trabajo colaborativo:

a) Busca que la colaboración aborde los problemas desde diferentes perspectivas articulando saberes.

b) Promueve el trabajo conjunto entre las personas para tener un abordaje más integral de los problemas y el logro de las metas.

c) Permite afrontar con más recursos y estrategias las situaciones de incertidumbre.

d) Tiene una misión ética: promover el diálogo entre las ideas, favorecer el encuentro entre las personas y crear lazos de solidaridad, en procura de una tierra patria humanizada (Tobón, 2015b).

Por su parte, la inclusión se relaciona con el trabajo colaborativo desde la socioformación a partir del replanteamiento tanto de los conceptos que se emplean en el campo educativo y social como de las acciones de mediación docente para la formación de los estudiantes. Con referencia al planteamiento conceptual de alumnos con Necesidades Educativas Especiales (NEE) asociadas o no a una discapacidad, que predomina en el currículo oficial de educación básica en México, en el enfoque socioformativo, se sugiere un cambio importante. En concreto, se propone eliminar los adjetivos: educativas, especiales y discapacidad y usar solamente el término: alumno con necesidades o alumno con dificultades para la formación (De la Oliva, Tobón, Pérez \& Romero, 2015).

Las acciones de mediación docente para la 
inclusión consideran imprescindible identificar las necesidades y dificultades que pueden interferir en la formación de los estudiantes, a través de una práctica docente metacognitiva (Tobón, 2013f) que permita diseñar estrategias diferenciadas y amplíen las oportunidades de formación, accesibilidad, participación y autonomía mediante un ambiente propicio para que los niños y jóvenes con necesidades o dificultades para la formación, desarrollen las competencias correspondientes a través del trabajo colaborativo. El trabajo colaborativo les genera mayores oportunidades para formarse con otros, orientándolos respecto a la definición de sus metas de aprendizaje, evaluándose de forma continua e involucrándolos en diálogos abiertos para escuchar sugerencias de mejora. Sin embargo, para implementar procesos de inclusión en las escuelas, se requiere de una colaboración sinérgica entre los docentes, padres de familia, directivos y autoridades educativas. Asimismo, es necesario que se vincule con servicios de apoyo a la educación y la creación de redes con otros sectores, como por ejemplo: sector salud, sector empresarial, asociaciones civiles, ONG, entre otras.

Desde la socioformación, la inclusión se refiere entonces al proceso mediante el cual las instituciones educativas logran que todos los estudiantes se formen y alcancen las metas definidas en los planes de estudio, con apoyo de los políticos, los empresarios, los directivos, los asesores, los docentes, la familia y la comunidad.

\section{Metodología del trabajo colaborativo}

Tal como se ha venido analizando a lo largo de los diferentes ejes del presente estudio, son múltiples los enfoques que abordan distintas modalidades de trabajo grupal y trabajo colaborativo. Por ende, existen también diversas propuestas metodológicas para su puesta en práctica en las aulas. Con el afán de realizar un comparativo de los elementos metodológicos planteados por la socioformación y otros enfoques, a continuación, se describe la metodología propuesta por Sharan (1992), basada en el trabajo cooperativo.

Tabla 8. Esquema de aplicación de la colaboración basado en el trabajo cooperativo

\begin{tabular}{|c|c|}
\hline $\begin{array}{c}\text { Elementos } \\
\text { metodológicos }\end{array}$ & Acciones clave \\
\hline $\begin{array}{l}\text { 1. Identificación } \\
\text { del tema }\end{array}$ & $\begin{array}{l}\text { Organización de los alumnos en grupos } \\
\text { de investigación, de no más de cuatro o } \\
\text { cinco miembros y heterogéneos. }\end{array}$ \\
\hline $\begin{array}{l}\text { 2. Planificación } \\
\text { de la tarea } \\
\text { de aprendizaje }\end{array}$ & $\begin{array}{l}\text { Los miembros del equipo deciden qué va } \\
\text { a ser estudiado, cómo va a ser estudiado, } \\
\text { el reparto del trabajo y la meta u objetivo } \\
\text { que se persigue. }\end{array}$ \\
\hline $\begin{array}{l}\text { 3. Realización dela } \\
\text { investigación }\end{array}$ & $\begin{array}{l}\text { Los estudiantes recogen información, } \\
\text { analizan datos, los evalúan y llegan a } \\
\text { conclusiones, mediante la participación } \\
\text { de los miembros del equipo y la } \\
\text { consulta al profesor y a compañeros } \\
\text { de equipos diferentes, lo que crea una } \\
\text { retroalimentación entre los alumnos, } \\
\text { imprescindible en el método. }\end{array}$ \\
\hline $\begin{array}{l}\text { 4. Preparación } \\
\text { del informe final }\end{array}$ & $\begin{array}{l}\text { El grupo concluye su tarea con la } \\
\text { elaboración de un informe, un resumen } \\
\text { o una demostración, cuya valoración } \\
\text { tendrá en cuenta el grado de organización, } \\
\text { abstracción y síntesis dela información. }\end{array}$ \\
\hline $\begin{array}{l}\text { 5. Exposición del } \\
\text { informe }\end{array}$ & $\begin{array}{l}\text { El método de exposición se decide } \\
\text { libremente dentro del grupo, en tanto que } \\
\text { para su valoración se tendrá en cuenta la } \\
\text { participación del auditorio. }\end{array}$ \\
\hline 6. Evaluación & $\begin{array}{l}\text { Se evalúa conjuntamente entre el profesor } \\
\text { y los alumnos el trabajo en grupo, la } \\
\text { exposición y el examen de evaluación } \\
\text { individual. }\end{array}$ \\
\hline
\end{tabular}

Fuente: Elaboración propia con datos de Sharan (1990).

En la socioformación, el trabajo colaborativo 
se aborda de acuerdo con las metas de formación que se esperan alcanzar en el currículo, considerando las necesidades y expectativas de los estudiantes, docentes, asesores educativos y los retos del contexto. Para que el trabajo colaborativo tenga impacto en los procesos formativos actuales es recomendable seguir las acciones metodológicas descritas en la Tabla 9 de manera sistemática y didáctica:

Tabla 9. Elementos metodológicos del trabajo colaborativo

\begin{tabular}{|c|c|}
\hline $\begin{array}{c}\text { Elementos } \\
\text { metodológicos }\end{array}$ & Acciones clave \\
\hline $\begin{array}{l}\text { Se establecen las } \\
\text { metas de formación }\end{array}$ & $\begin{array}{l}\text {-Con base en los planes y programas } \\
\text { de estudio se determinan las metas de } \\
\text { aprendizaje que serán socializadas, } \\
\text { acordadas y evaluadas con los } \\
\text { estudiantes. } \\
\text {-Se establece el proceso de vinculación } \\
\text { y transversalidad entre las distintas áreas } \\
\text { del conocimiento. }\end{array}$ \\
\hline $\begin{array}{l}\text { Un problema } \\
\text { del contexto }\end{array}$ & $\begin{array}{l}\text {-Se identifica, argumenta, interpreta y } \\
\text { socializaunanecesidad del contexto que } \\
\text { es importante y pertinente abordar para } \\
\text { mejorar el entorno. } \\
\text {-Se establece la meta o propósito a } \\
\text { alcanzar a través del trabajo colaborativo } \\
\text { para abordar la necesidad acordada. }\end{array}$ \\
\hline Plan de acción & $\begin{array}{l}\text {-Se establecen las acciones puntuales } \\
\text { a desarrollar para resolver el problema } \\
\text { (necesidad, obstáculo o vacío), asícomo } \\
\text { los tiempos y recursos necesarios. }\end{array}$ \\
\hline $\begin{array}{l}\text { Asignación } \\
\text { de roles }\end{array}$ & $\begin{array}{l}\text {-Cada participante asume un rol con } \\
\text { conciencia de las propias habilidades y } \\
\text { las acciones arealizar. } \\
\text {-Los roles son dinámicos, por lo que } \\
\text { se sugiere puedan rotarse a lo largo del } \\
\text { trabajo colaborativo. }\end{array}$ \\
\hline $\begin{array}{l}\text { Socialización } \\
\text { de evidencias } \\
\text { generadas }\end{array}$ & $\begin{array}{l}\text {-Argumentación de las evidencias } \\
\text { elaboradas, así como el impacto } \\
\text { producido de forma real o simulada } \\
\text { para resolver el problema del contexto } \\
\text { establecido. }\end{array}$ \\
\hline
\end{tabular}

Tabla 9. Continuación

\begin{tabular}{|c|c|}
\hline $\begin{array}{l}\text { Valoración } \\
\text { del proceso } \\
\text { y las } \\
\text { evidencias } \\
\text { socializadas }\end{array}$ & $\begin{array}{l}\text {-De acuerdo con las metas establecidas, } \\
\text { los criterios de evaluación y las evidencias } \\
\text { aevaluar, se establece un instrumento de } \\
\text { evaluación que emplea indicadores o } \\
\text { niveles de desempeño (Mosqueda, 2013); } \\
\text { por ejemplo: mapas de aprendizaje o } \\
\text { rúbricas socioformativas. }\end{array}$ \\
\hline $\begin{array}{l}\text { Proceso } \\
\text { metacognitivo } \\
\text { del trabajo } \\
\text { colaborativo }\end{array}$ & $\begin{array}{l}\text {-Se identifica el nivel de desempeño } \\
\text { alcanzado a partir del instrumento de } \\
\text { evaluación implementado. } \\
\text {-Se comparten los logros y aspectos } \\
\text { a mejorar a partir de la evaluación } \\
\text { realizada, se asumen compromisos y se } \\
\text { emprenden acciones de mejora. }\end{array}$ \\
\hline
\end{tabular}

Fuente: Elaboración propia

\section{Ejemplificación del trabajo colaborativo}

Existen múltiples ejemplos de aplicación del trabajo colaborativo, considerando el tipo de problema, las personas a quienes está dirigido y las metas de desempeño, entre otros aspectos. El siguiente ejemplo fue planteado como parte de un proyecto formativo realizado en la asignatura de Psicología Escolar y Educativa correspondiente al tercer semestre de la Licenciatura en Psicología, buscando mejorar las prácticas docentes según los retos de la sociedad del conocimiento.

Tabla 10. Ejemplo de aplicación del trabajo colaborativo

\begin{tabular}{|l|l|}
\hline $\begin{array}{l}\text { Proyecto } \\
\text { formativo: }\end{array}$ & $\begin{array}{l}\text { Tecnología para pensar más y no escribir } \\
\text { menos... }\end{array}$ \\
\hline $\begin{array}{l}\text { Nivel } \\
\text { educativo: }\end{array}$ & Educación Superior \\
\hline Semestre: & Tercero \\
\hline País: & México \\
\hline $\begin{array}{l}\text { Asignaturas } \\
\text { que se } \\
\text { vincularon: }\end{array}$ & $\begin{array}{l}\text { Bases Biológicas de la Conducta, TIC y } \\
\text { Psicología Escolar y Educativa. }\end{array}$ \\
\hline $\begin{array}{l}\text { Elementos } \\
\text { metodológicos }\end{array}$ & Acciones clave \\
\hline
\end{tabular}




\begin{tabular}{|c|c|}
\hline $\begin{array}{l}\text { 1. Se establecen } \\
\text { las metas de } \\
\text { formación }\end{array}$ & $\begin{array}{l}\text {-Resultado de aprendizaje: "utiliza el } \\
\text { lenguaje para estructurar coherentemente su } \\
\text { pensamiento y su discurso para participar } \\
\text { en eventos comunicativos en distintos } \\
\text { contextos". } \\
\text {-Para lograr la transversalidad se han } \\
\text { considerado resultados de aprendizaje } \\
\text { de otras asignaturas tales como: Bases } \\
\text { Biológicas de la Conducta, TICy Psicología } \\
\text { Escolar y Educativa. Todas ellas se cursan } \\
\text { en el mismo semestre. Los profesores sehan } \\
\text { reunido para diseñar el trabajo colaborativo y } \\
\text { formar con el ejemplo. }\end{array}$ \\
\hline $\begin{array}{l}\text { 2. Problema del } \\
\text { contexto }\end{array}$ & $\begin{array}{l}\text {-Se analizaron diferentes problemáticas } \\
\text { generadas por el uso de móviles, tabletas, } \\
\text { celulares, etc. en la actualidad y su impacto } \\
\text { en las relaciones interpersonales en distintos } \\
\text { contextos. } \\
\text {-La necesidad que se identificó fue: "el } \\
\text { uso del lenguaje a partir del manejo de la } \\
\text { tecnología está generando transformaciones } \\
\text { significativas en las nuevas generaciones; sin } \\
\text { embargo, este tema al no serprofundizadoes } \\
\text { motivo de conflicto entre adultos y jóvenes, } \\
\text { principalmente". } \\
\text {-El reto o meta consiste en utilizar la } \\
\text { tecnología como medio de producción de } \\
\text { lenguaje que exprese la transformación del } \\
\text { pensamiento en las generaciones del siglo } \\
\text { XXI y, así, lograr espacios y momentos } \\
\text { de diálogo que favorezcan la unidad y la } \\
\text { convivencia pacífica. }\end{array}$ \\
\hline \multirow[t]{2}{*}{$\begin{array}{l}\text { 3. Plan de } \\
\text { acción }\end{array}$} & $\begin{array}{l}\text {-Los estudiantes se organizan en equipos } \\
\text { de } 4 \text { integrantes y elaboran un programa } \\
\text { de actividades que realizarán para abordar } \\
\text { el problema. Entre ellas se encuentran: a) } \\
\text { encuesta sobre el tiempo y uso del celular en } \\
\text { las familias, b) recabar información sobre el } \\
\text { uso de las TIC en la mejora de las relaciones } \\
\text { familiares, c) investigar APPS (aplicaciones) } \\
\text { en Internet que promuevan la comunicación }\end{array}$ \\
\hline & $\begin{array}{l}\text { familiar, y d) diseño de un test psicológico que } \\
\text { ayude a identificar el nivel de comunicación } \\
\text { familiary los tipos demensajes que se emiten } \\
\text { entre padres e hijos. } \\
\text {-Se establecen tiempos de entrega de avances, } \\
\text { los recursos necesarios para realizar estas } \\
\text { actividades y los responsables de las mismas. }\end{array}$ \\
\hline $\begin{array}{l}\text { 4. Asignación } \\
\text { de roles }\end{array}$ & $\begin{array}{l}\text {-Se asignan los siguientes roles: dinamizador, } \\
\text { coordinador, gestor de calidad y } \\
\text { sistematizador. Los estudiantes deciden rotar } \\
\text { estas responsabilidades cada semana, por lo } \\
\text { cual, deberán realizar las actividades según } \\
\text { el plan establecido, para evitar confusión y } \\
\text { desfase en la entrega. }\end{array}$ \\
\hline
\end{tabular}

Tabla 10. Continuación

\begin{tabular}{|c|c|}
\hline $\begin{array}{l}\text { 5. Socialización } \\
\text { de los } \\
\text { productos o } \\
\text { evidencias } \\
\text { generadas }\end{array}$ & $\begin{array}{l}\text {-De acuerdo con elplan de acción establecido } \\
\text { anteriormente, se organiza una presentación } \\
\text { de los productos generados, así como de los } \\
\text { resultados de la encuesta y el test elaborado } \\
\text { para medir el impacto de las TIC en la } \\
\text { comunicación familiar. } \\
\text {-Seinvitaa los padres de familia para conocer } \\
\text { los resultados del trabajo realizado de forma } \\
\text { colaborativa. } \\
\text {-Se sugiere a los padres de familia realizar } \\
\text { un autoanálisis del nivel de uso de las TIC } \\
\text { para mejorar la comunicación con sus hijos } \\
\text { y cónyuges. }\end{array}$ \\
\hline $\begin{array}{l}\text { 6. Valoración } \\
\text { del proceso y } \\
\text { las evidencias } \\
\text { socializadas }\end{array}$ & $\begin{array}{l}\text {-Los estudiantes utilizan los instrumentos } \\
\text { de evaluación socializados al inicio del } \\
\text { trabajo colaborativo, en donde se consideran } \\
\text { las metas (resultado de aprendizaje), las } \\
\text { evidencias elaboradas en el proceso y los } \\
\text { indicadores de calidad que se presentaron } \\
\text { anteriormente. } \\
\text {-Losinstrumentos incluyeron: lista de cotejo } \\
\text { de la encuesta, rúbrica de la investigación } \\
\text { del uso de las TIC, lista de cotejo de la } \\
\text { investigación de las aplicaciones en Internet } \\
\text { y rúbrica del diseño del test psicológico. }\end{array}$ \\
\hline $\begin{array}{l}\text { 7. Proceso } \\
\text { metacognitivo } \\
\text { del trabajo } \\
\text { colaborativo }\end{array}$ & $\begin{array}{l}\text {-Los padres de familia realizaron una } \\
\text { socioevaluación a partir de lo compartido } \\
\text { en la socialización de las actividades y las } \\
\text { evidencias. Sugirieron algunas mejoras en los } \\
\text { instrumentos aplicados (encuesta y test). } \\
\text {-Los estudiantes se autoevaluaron empleando } \\
\text { los instrumentos socializados para este } \\
\text { fin. Identificaron los indicadores que se } \\
\text { cumplieron, así como el nivel de desempeño } \\
\text { alcanzado en las evidencias correspondientes. } \\
\text {-Finalmente, se realizó la coevaluación para } \\
\text { estableceraccionesdemejoraenlaspróximas } \\
\text { presentaciones a padres de familia. }\end{array}$ \\
\hline
\end{tabular}

Fuente: Elaboración propia

\section{Discusión}

A diferencia de los modelos individualistas, el método colaborativo favorece la cohesión social, la autoestima, la participación y el pensamiento crítico, así como el desarrollo de competencias intelectuales y profesionales (Lanza \& Barrios, 2012). El trabajo colaborativo desde la socioformación es una propuesta metodológica 
que busca la integralidad y ello implica que se trabaje de forma conjunta con otras estrategias de formación y evaluación de competencias como: proyectos formativos (Juárez \& Torres, 2016), docencia socioformativa (Hernández, Tobón \& Vasquez, 2014), portafolio de evidencias (Hernández, Tobón \& Vázquez, 2015a), entre otras. En consecuencia, el trabajo colaborativo trasciende a otras modalidades de trabajo: en equipo, en masa y cooperativo. Estas últimas formas de organización, tanto escolar como laboral, son características de la educación tradicional y de la sociedad industrial que únicamente buscan la distribución de responsabilidades entre el colectivo y la competitividad (rivalidad), entre los miembros de las organizaciones (Hernández, 2015b), como ya se distinguió en otro momento. Bajo la metodología propuesta los estudiantes o miembros se enriquecen unos a otros, se complementan, generan alianzas y acuerdos que permiten alcanzar metas planteadas con antelación, lo cual exige un trabajo consciente y comprometido por parte de cada uno de los integrantes.

Además, al trabajar colaborativamente, se favorece el liderazgo en los miembros de las organizaciones (estudiantes, empresarios, directivos), mediante el establecimiento de criterios, evidencias a realizar y planes de acción que pueden ser evaluados y mejorados con base en la metodología socioformativa (Tobón, 2001, 2002, 2004, 2013b). Este liderazgo les permite analizar la forma de influir en las personas utilizando el diálogo razonado y el manejo de argumentos tras identificar en el otro aspectos que le permitan encontrar puntos de coincidencia y subsanar las diferencias (Hernández, Tobón \& Vázquez, 2015b). Lo anterior revela que los acuerdos son fundamentales en la colaboración, ya que sin estos las metas, actividades, organización y demás aspectos inherentes no se pueden lograr. En suma, mediante el trabajo colaborativo se contribuye a la aplicación de los principios del pensamiento complejo (Morin, 1994, 1996, 1997, 2000), y de forma paralela, se aporta a la sociedad del aprendizaje (UNESCO, 2005); sin embargo, es importante seguir profundizando la relación entre estos y la tierra patria (Morin \& Kern, 1993) a través de nuevas investigaciones.

\section{Conclusión}

La sociedad y la educación actual demandan grandes cambios, mejoras e innovaciones que den respuesta a los retos que los diversos contextos requieren en su complejidad. Las múltiples reformas educativas impulsadas actualmente en diversos países, han convergido en torno a la modernización curricular de sus distintos niveles educativos para lograr el desarrollo de competencias en los estudiantes que les permitan retener, comprender y analizar información, amén de argumentar, trabajar en equipo y estructurar sus ideas para comunicarlas adecuadamente (Kirschner, Paas, \& Kirschner, 2009). Para que se logre el aprendizaje colaborativo, es indispensable que exista una interdependencia positiva, responsabilidad individual, interacción directa y enseñanza deliberada de habilidades sociales (Iborra \& Izquierdo, 2010). 
Por ello, este estudio enfatiza la relevancia del trabajo colaborativo desde la socioformación, como una metodología didáctica factible que puede ponerse en práctica desde el ámbito personal hasta el institucional/organizacional y contribuir con el desarrollo de un conocimiento complejo que articule y movilice los saberes para capitalizarlos en competencias.

El enfoque socioformativo reconoce la relevancia de la colaboración y el pensamiento complejo para transformar la educación en un proceso innovador y creativo, que redunde en la formación de seres humanos competentes y democráticos. De ahí la importancia de continuar con estudios y análisis que pongan énfasis en las características y elementos metodológicos del trabajo colaborativo para la transformación de las prácticas educativas y organizacionales en todos los niveles. Es indispensable promover procesos investigativos empíricos que contribuyan a validar y mejorar dicha metodología, a fin de consolidarla como una respuesta a la formación de personas integrales y con un sólido y ético proyecto de vida.

\section{Referencias}

Acosta, H. P., Tobón, S., \& Loya, J. L. (2015). Docencia socioformativa y desempeño académico en la educación superior. Paradigma, 36(1), 42-55.

Antonijevic, N. \& Chadwick, C. (1981). Estrategias Cognitivas y Metacognición. Revista de Tecnología Educativa, 7(4), 307-321.
Ausubel, D. (1976). Psicología educativa. México: Trillas.

Bartolucci, J. (2002). La polarización educativa en México: la élite y la masa. México: Centro de Estudios sobre la Universidad -UNAM.

Beltrán, J. \& Bueno, J. A. (Eds.) (1997). Psicología de la Educación. México: Alfaomega Grupo Editor.

Buzán, T. (2004). Mind Maps at Work: How to Be the Best at Your Job and Still Have Time to Play. USA: PLUMA.

Bruning, R. H., Schraw, G. J. \& Ronning, R. R. (2002). Psicología cognitiva e instrucción. España: Alianza Editorial.

Cano, M. (1996). La investigación colaborativa en educación. Ciencia Administrativa, Vol. Especial, 55-59.

Carretero, M. (2009). Constructivismo y Educación. Buenos Aires: Paidós.

Calzadilla, M. (2002). Aprendizaje Colaborativo y Tecnologías de la Información Y La Comunicación. Revista Iberoamericana de Educación, (30), 1-10.

Chaves, S., A. L. (2001). Implicaciones educativas de la teoría sociocultural de Vigotsky. Educación, 25(002), 56-65.

De la Oliva, D., Tobón, S., Pérez, S. A. K. \& Romero, J. (2015). El Proceso de Inclusión Social desde la Socioformación: Análisis de Concepciones sobre Discapacidad y Necesidades Educativas Especiales. Paradigma, 36(2), 49-73.

Díaz, B., F. (2003). Cognición situada y estrategias para el aprendizaje significativo. Revista Electrónica de Investigación Educativa, 5(2). Consultado el 12 de 
agosto de 2015 en: http://redie.ens.uabc. $\mathrm{mx} / \mathrm{vol} 5 \mathrm{no} 2 /$ contenido-arceo.html

Díaz-Barriga, F. \& Hernández, G. (2010). Estrategias docentes para un aprendizaje significativo una interpretación constructivista. México: Mc Graw-Hill Interamericana.

DOF (2012). Acuerdo número 649 por el que se establece el Plan de estudios para la Formación de Maestros de Educación Primaria (14), p. 6.

Domínguez-Gaona, M. R., Crhová, J. \& MolinaLanderos, R. C. (2015). La investigación colaborativa: las creencias de los docentes de lenguas. Revista Iberoamericana de Educación Superior, 17, 119-134.

Feo, R. (2015). Epistemología y práctica de la investigación sobre el aprendizaje estratégico en América Latina. Revista Educación y Humanismo, 17 (29), 220-235. http://dx.doi.org/10.17081/ eduhum.17.29.1254

Ferreiro, G. R. (2006). Nuevas alternativas de aprender y enseñar: aprendizaje cooperativo. México: Trillas.

Germani, C. (1962). Política y sociedad en una época de transición. De la sociedad tradicional a la sociedad de masas. Buenos Aires: Paidós.

Gibbons, M. (1998). Higher Education Relevance in the 21st Century, Washington, The World Bank. Recuperado de: http://siteresources.worldbank. org/EDUCATION/Resources/2782001099079877269/5476641099079956815/

Higher_ed_relevance_in_21st_century_ En98.pdf

Hernández, M., J. S. (2013a). Formación de docentes para el siglo XXI. Guía para el desarrollo de competencias docentes. México: Santillana.

Hernández, J. S. (2013b). Procesos de evaluación de las competencias desde la socioformación. Ra Ximhai, 9(4), 11-19.

Hernández, J. S. (2015a). Guía para el desarrollo de competencias en la Educación Media Superior. México: Santillana.

Hernández, J. S. (2015b). Coaching socioformativo. Estrategia para el liderazgo directivo. Revista Multiversidad Management, 22, 55-54.

Hernández M, J., Tobón, S. \& Vázquez, A., J. (2014). Estudio conceptual de la docencia socioformativa. Ra Ximhai: El mundo, el universo, la vida, 10(5), 89-99.

Hernández, J. S. \& Vizcarra, J. J. (2015). Didáctica para la formación integral en la sociedad del conocimiento. México: Horson Ediciones.

Hernández, J. S., Guerrero, G. \& Tobón, S. (2015). Los problemas del contexto: base filosófica y pedagógica de la socioformación. Revista Ra Ximhai, 11(4), 125-140.

Hernández, J. S., Tobón, S., González, L. \& Guzmán, C. (2015). Evaluación socioformativa y rendimiento académico en un programa de posgrado en línea. Paradigma, 36(1), 30-41.

Hernández, J. S., Nambo, J. S., López, J. \& Núñez, A. C. (2015). Estudio del coaching socioformativo mediante la cartografía conceptual. Revista Acción Pedagógica, (23) (enero-diciembre), 94-105.

Hernández, J. S., Tobón, S. \& Vázquez, J. M. 
(2015a). Estudio documental del portafolio de evidencias mediante la cartografía conceptual. Revista de Evaluación Educativa, 4(1),

Hernández, J. S., Tobón, S. \& Vázquez J. M. (2015). Estudio del Liderazgo Socioformativo mediante la Cartografía Conceptual. Revista Iberoamericana de Evaluación Educativa, 8(2), 105-128.

Hernández, J. S., Tobón, S. \& Guerrero, G. (2016). Hacia una evaluación integral del desempeño: las rúbricas socioformativas. Ra Ximhai, 12(6), 359-376.

Hopenhayn, M. (2003). Educación, comunicación y cultura en la sociedad de la información: una perspectiva latinoamericana. Santiago de Chile: Naciones Unidas/CEPAL.

Iborra, C. A. \& Izquierdo, A. M. (2010) ¿Cómo afrontar la evaluación del aprendizaje colaborativo? Una propuesta valorando el proceso, el contenido y el producto de la actividad grupal. Revista General de Información y Documentación, 20, 221-241.

Inhelder, B. \& Piaget, J. (1972). De la lógica del niño a la lógica del adolescente. Buenos Aires: Paidós.

Janasz, S. \& Sullivan, S. (2004). Multiple Mentoring in Academe: Developing the professorial network. Journal of Vocational Behavior, 64(2), 263-283.

Juárez, D. \& Torres, C. (2016). Proyectos Formativos de Investigación: Análisis de una Experiencia. Revista Atlante: Cuadernos de Educación y Desarrollo, (73). http:// www.eumed.net/rev/atlante/2016/07/ proyectos.html
Kirschner, F., Paas, F. \& Kirschner, A. P. (2009) A Cognitive Load Approach to Collaborative Learning: United Brains for Complex Tasks. Education Psychology, (21), 31-42.

Krüger, K. (2006). El concepto de sociedad del conocimiento. Revista bibliográfica de geografía y ciencias sociales, 11(683), 117.

Lanza, E. D. \& Barrios, F. A. (2012). Aprendizaje cooperativo como fórmula para el desarrollo de competencias en el Espacio Europeo de Educación superior: un estudio exploratorio con alumnos de Psicología de la Universidad Autónoma de Madrid. Congreso Internacional de Docencia Universitaria e Innovación, Barcelona, España.

Lee, S. H. \& Bozeman, B. (2005). The impact of research collaboration on scientific productivity. Social Studies of Science, 35, 673-702.

Loan-Clark, J. \& Preston, D. (2002). Tensions and benefits in collaborative research involving a university and another organization. Studies in Higher Education, 27(2), 169-185.

Londoño, P., O., L., Maldonado, G., L. F. \& Calderón, V., L., C. (2014). Guía para construir estados del arte. Bogotá: ICNK. Lucas, A. M. (2000). La nueva sociedad de la información. Una perspectiva desde Silicon Valley. España: Trotta.

Maldonado, P. M. (2007). El trabajo colaborativo en el aula universitaria. Laurus, 13(23), 263-278. Recuperado de http://www. redalyc.org/articulo.oa?id=76102314 
Marcelo, C. (2001). Aprender a enseñar para la sociedad del conocimiento. Revista complutense de educación, 12(2), 531593.

Martín, A. G. (1997). Educación multimedia y nuevas tecnologías. Madrid: Ediciones La Torre.

Martín, A. G. (2007). Integración curricular de las TIC y educación para los medios en la sociedad del conocimiento. Revista Iberoamericana de educación, 45, 141156.

Mateo, J. L. (2006). Sociedad del conocimiento. Arbor, 182(718), 145-151.

Mora, J. G. (2004). La necesidad del cambio educativo para la sociedad del conocimiento. Revista Iberoamericana de educación, 35(2), 13-37.

Morin, E. (1994). El método III. El conocimiento del conocimiento. Madrid: Cátedra.

Morin, E. (1996). Introducción al pensamiento complejo. Barcelona: Gedisa.

Morin, E. (1997). La necesidad de un pensamiento complejo. En S. González (Ed.), Pensamiento complejo. En torno a Edgar Morin, América Latina y los procesos educativos. Bogotá: Cooperativa Editorial Magisterio.

Morin, E. (2000). Los siete saberes necesarios para la educación del futuro. Bogotá: Ministerio de Educación Nacional.

Morin, E. \& Kern, A. B. (1993). Tierra-patria. España: Kairós.

Nobles, D., Londoño, L., Martínez, S., Ramos, A., Santa, G. \& Cotes, A. (2016). Tecnologías de la comunicación y relaciones interpersonales en jóvenes universi- tarios. Revista Educación y Humanismo, 18(30), 14-27. http://dx.doi.org/10.17081/ eduhum.18.30.1311/

Mosqueda, J. (2013). Procesos de evaluación de las competencias desde la socioformación. Revista Ra Ximhai, 9(4), 11-19. Disponible en: http://www.redalyc.org/ articulo. oa? $\mathrm{id}=46129004001$

Novak, J. D. (2010). Learning, creating, and using knowledge: Concept maps as facilitative tools in schools and corporations (Second edition). New York: Routledge.

Onrubia, J., Colomina, R., \& Engel, A. (2008). Los entornos virtuales de aprendizaje basados en el trabajo en grupo y el aprendizaje colaborativo. Psicología de la educación virtual (pp.233-252). Madrid: Morata.

Ortega-Carbajal, F., Hernández, J. S. \& Tobón, S. (2015a). Análisis documental de la gestión del conocimiento mediante la cartografía conceptual. Ra Ximhai, 11(4), 141-160.

Ortega-Carbajal, F., Hernández, J. S. \& Tobón, S. (2015b). Impacto de la cartografía conceptual como estrategia de gestión del conocimiento. Ra Ximhai, 11(4), 171-180.

Parra-Acosta, H. P., Tobón, S. \& Loya, J. L. (2015). Docencia socioformativa y desempeño académico en la educación superior. Paradigma, 36(1), 42-55.

Pastor, M. L. C. (2007). Ventajas del uso de la tecnología en el aprendizaje colaborativo. Revista Iberoamericana de Educación, 41(4).

Perkins, D. (1997). La escuela inteligente. Del adiestramiento de la memoría a la 
educación de la mente. Barcelona: Gedisa.

Pinto, M. \& Gálvez, C. (1996). Análisis documental de contenido. Vallehermoso: Síntesis.

RAE (2017). Diccionario de la lengua española. Madrid: Real Academia Española.

Siemens, G. (2005). Connectivism: A Learning Theory for the Digital Age. International Journal of Instructional Technology, and Distance Learning, 2(1).

Stone W., M. (1999). La enseñanza para la comprensión. Vinculación entre la investigación y la práctica. Buenos Aires: Paidós.

Swanson, H. L. (1990). Influence of Metacognitive Knowledge and Aptitude on Problem Solving. Journal of Educational Psychology, 82(2), 306-314.

Sharan, Y. (1992). Expanding Cooperative Learning Through Cooperative Learning. New York: Teachers College Press. Disponible en: http://calidad.ugr.es/tutoria/ materiales_asistentes/aprendizaje-cooperativo-en-grupos/!. Recuperado el 20 de septiembre de 2016

Stehr, N. (1994). Eigentum und Wissen. Zur Theorie von Wissensgesellschaften. Frankfurt: Suhrkamp.

Tedesco, J. C. (2000). Educación y sociedad del conocimiento y de la información. Revista Colombiana de la Educación, 6.

Terroni, N. N. (2009). La comunicación y la asertividad del discurso durante las interacciones grupales presenciales y por computadora. PsicoUSF, 14(1), 35-46.

Tobón, S. (2001). Aprender a emprender. Un enfoque curricular. Medellín: Funorie.
Tobón, S. (2002). Modelo pedagógico basado en competencias. Medellín: Funorie.

Tobón, S. (2004). Formación basada en competencias. Pensamiento complejo, diseño curricular y didáctica. Bogotá: ECOE.

Tobón, S. \& Núñez, A. C. (2006). La gestión del conocimiento desde el pensamiento complejo: Un compromiso ético con el desarrollo humano. Revista EAN, 58, 2740.

Tobón, S. (2010). Proyectos formativos: metodología para el desarrollo y evaluación de competencias. México: Book Mart.

Tobón, S. (2011). El modelo de las competencias en la educación desde la socioformación. En A. Jaik y A. Barraza (Coords.). Competencias y educación. Miradas múltiples de una relación (pp.14-24). México:REDIE.

Tobón, S. (2012a). Sociedad global y educación por competencias. México: CIFE.

Tobón, S. (2012b). Experiencias de aplicación de las competencias en la educación y el mundo organizacional. México: CIFE.

Tobón, S. (2013a). Trabajo colaborativo e interaprendizaje. México: CIFE.

Tobón, S. (2013b). Formación integral y competencias: pensamiento complejo, currículo, didáctica y evaluación. $4^{\mathrm{a}}$ edición. Bogotá: Ecoe Ediciones.

Tobón, S. (2013c). Socioformación. Los retos de la educación en la sociedad del conocimiento. Multiversidad Management, 4, 32-37.

Tobón, S. (2013d). El enfoque socioformativo de las competencias: Aplicando el pensamiento complejo en el aula. En M. M. Alonso y M.N. Ruiz (Coords.), Educación 
por competencias. Crítica y perspectivas (pp.125-147). Toluca (México): FronterAbierta.

Tobón, S. (2013e). La evaluación de las competencias en la educación básica (2da. Ed.). México: Santillana.

Tobón, S. (2013f). Diez acciones esenciales para formar y evaluar las competencias. México: CIFE.

Tobón, S. (2014). Proyectos formativos: teoría y metodología. México: Pearson.

Tobón, S. (2015a). Cartografía conceptual: estrategia para la formación y evaluación de conceptos y teorías. México: CIFE.

Tobón, S. (2015b). Socioformación: hacia la gestión del talento humano acorde con la sociedad del conocimiento. México: CIFE.

Tobón, S. \& Vázquez, J. M. (2015). Trabajo colaborativo: acciones para su implementación en la gestión del talento humano y la docencia. Multiversidad Management, 19, 36-42.

Tobón, S., Guzmán, C. E., Hernández, J. S. \& Cardona, S. (2015). Sociedad del conocimiento: Estudio documental desde una perspectiva humanista y compleja. Paradigma, 36(2), 7-36.

Tobón, S., González, L., Nambo, J. S. \& Vázquez, J. M. (2015). La Socioformación: Un Estudio Conceptual. Paradigma, 36(1), 7-29.
Tobón, S., Cardona, S., Vélez, J. \& López, J. (2015). Proyectos formativos y desarrollo del talento humano para la sociedad. Acción Pedagógica, 24(1), 20-31.

Trejo, R. (2001). Monográfico La sociedad de la información. Vivir en la sociedad de la información. Orden global y dimensiones locales en el universo digital. Revista Iberoamericana de Ciencia, Tecnología, Sociedad e Innovación, (1). Recuperada de www.oei.es/revistactsi/numero1/trejo.htm Ulrich,

B. (2003). La sociedad del riesgo global. Revista Española de Investiga- ciones Sociológicas, (101) (enero-marzo), 279-283.

UNESCO (2005). Hacia las sociedades del conocimiento. París: UNESCO.

Vygotsky, L. S. (1979). El desarrollo de los procesos psicológicos superiores. Buenos Aires: Grijalbo.

Vygotsky, L. S. (1981). Pensamiento y Lenguaje. Buenos Aires: La Pléyade.

Woolfolk, A. (2010). Psicología educativa. 11a. edición. México: Pearson.

Yussen, S. (1985). The Rol of Metacognition in Contemporary Theories of Cognitive Development. En D. L. Forrest-Presley, G.E. Mackinson, y T. G. Waller (Eds). Metacognition, Cognition and Human Performance. 1. Theoretical Perspectives. (pp.253-283). New York: Academic Press. 